\title{
Effects of negatively and positively charged Ti metal surfaces on ceramic coating adhesion and cell response
}

\author{
Rodney Marcelo do Nascimento ${ }^{1,2}$ - Vanessa Rafaela de Carvalho ${ }^{3}$. \\ José Silvio Govone ${ }^{4}$ - Antônio Carlos Hernandes ${ }^{1} \cdot$ Nilson Cristino da $\mathrm{Cruz}^{2}$
}

Received: 4 October 2016 / Accepted: 4 January 2017 / Published online: 20 January 2017

(C) Springer Science+Business Media New York 2017

\begin{abstract}
This manuscript reports an evaluation of the effects of simple chemical-heat treatments on the deposition of different ceramic coatings, i.e., $\mathrm{TiO}_{2}, \mathrm{CaTiO}_{3}$ and $\mathrm{CaP}$, on commercially pure titanium (cp-Ti) and Ti6Al4V and the influence of the coatings on cells interaction with the surfaces. The ceramic materials were prepared by the sol-gel method and the coating adhesion was analyzed by pull-off bending tests. The wettability of positively or negatively charged surfaces was characterized by contact angle measurements, which also enabled the calculation of the surface free energy through the polar-apolar liquids approach. Both acid and alkaline treatments activated the cp-Ti, whereas Ti6Al4V was only activated by the alkaline treatment. Such treatment led to increased hydrophilicity with inhibition of the fibroblastic response on Ti6Al4V. On the other hand, osteoblastic cells adhered to and proliferated on the positively and negatively charged surfaces. The maximum
\end{abstract}

Electronic supplementary material The online version of this article (doi:10.1007/s10856-017-5848-0) contains supplementary material, which is available to authorized users.

Rodney Marcelo do Nascimento

rodneymn@ifsc.usp.br

rodney.nascimento79@gmail.com

1 São Carlos Institute of Physics, University of São Paulo, USP, PO Box 369, 1356-6590 São Carlos, SP, Brazil

2 Laboratory of Technologycal Plasmas, Universidade Estadual Paulista, UNESP, Sorocaba, SP, Brazil

3 Departamento de Microbiologia, Universidade Estadual Paulista, UNESP, Botucatu, SP, Brazil

4 Departamento de Estatística Matemática Aplicada e Computação, Universidade Estadual Paulista, UNESP, Rio Claro, SP, Brazil adhesion strength $(\sim 3400 \mathrm{~N})$ was obtained with a negative $\mathrm{Ti} \mathrm{Al} 14 \mathrm{~V}-\mathrm{CaTiO}{ }_{3}-\mathrm{CaP}$ multilayer surface.

\section{Graphical Abstract}

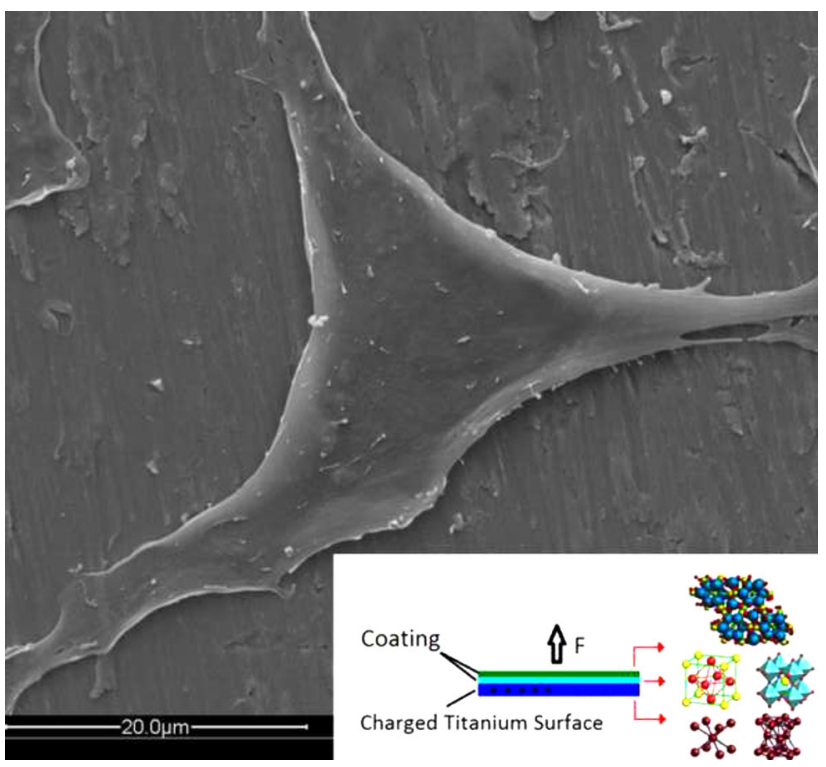

\section{Introduction}

Optimized implants that promote high bone anchorage exhibit interesting surface properties for osseointegration [1-4]. Among such biomaterials, calcium phosphate-based coatings of titanium implants combine the favorable biological responses of the bioceramics [5-8] and the mechanical properties of metals $[9,10]$. However, despite its excellent bioactive performance, the low bond strength 
between bioceramics and $\mathrm{Ti}$ alloys may limit its applications due to incompatible interface crystallographic orientations, thermal expansion coefficients and chemical resistances.

Several very recent articles have discussed the key physic-chemical process on the production and clinical use of implants made from titanium and its alloys after surface treatments and coatings [11-14]. In addition to the acceleration of osseointegration, modifications on the surface potentially confer improved protection from chemical corrosion exerted by body fluids. For instance, the use of implants made from Ti6Al4V requires specific coatings to act as a barrier to avoid the leaching of Aluminum from the metallic surfaces. It has been shown that $\mathrm{TiO}_{2}$ intermediate layers can be the key for an effective shielding against the corrosion of the substrate [15].

Different surface modifications for $\mathrm{Ti}$ and Ti-based alloys have been proposed to improve the metal-bone interface [16-20]. In particular, the use of alkaline or acid heat-treatments has drawn attention due to the simple methodology applied for the activation of surfaces intermediated by titanium oxide structuration [21, 22]. Kokubo and Yamaguchi [21] described the effects of titanate layers on titanium and alloys obtained through simple chemicalthermal treatments. Such approach promotes the formation of apatite coatings on titanium-titanate surfaces after the soaking of the samples in a simulated body fluid. Under certain conditions, the optimized surface appears to improve the bone-material interface. Both positively charged $\mathrm{TiO}_{2}$ and negatively charged sodium titanate $\left(\mathrm{Na}_{2} \mathrm{TiO}_{3}\right)$ surfaces can promote the formation of apatite on the implants. However, the acid-heat treatment is not effective for apatite formation on some alloys. On the other hand, the alkalineheat treatment is not effective when alloying elements suppress the releasing of sodium ions. In summary, both positively and negatively charged surfaces affect the osteoconductivity. Different bone-surface connections obtained through simple approaches may lead to rejection of the material after implantation. Therefore, research is required to develop simple chemical-thermal treatments able to produce biomaterial surfaces with enhanced performance.

This manuscript addresses the role of acid and alkaline treatments of metallic implants and reports an experimental study of modified cp-Ti and Ti6Al4V surfaces. The effect of acid-alkaline treatments on wetting properties as evaluated from free surface energy and contact line dynamics investigations was evaluated. Such features were correlated qualitatively in terms of cell morphologies and quantitatively by cell viability essays. The role of acid-alkaline treatments on adhesion forces of different ceramic coatings was also tested. For all the coatings, the failures under the forces applied were almost negligible with the intermediary chemical heat treatments. As a main finding of this work, a new multilayered coating has emerged as a promising optimized surface for biomedical applications.

\section{Materials and methods}

\subsection{Acid and alkaline treatments}

The samples of $\mathrm{cp}$-Ti and Ti6Al4V $1.0 \times 1.0$ and $5.0 \times 5.0 \mathrm{~cm}^{2}$ in size were wet ground with 280,400 and 1200 mesh sandpapers. After washing in tap water, the samples were dipped in $\mathrm{HCl}$ and $\mathrm{NaOH}$ solutions, cleaned 3 times in ultrasonic bath with ultrapure water for $10 \mathrm{~min}$ and dried at $100^{\circ} \mathrm{C}$ for $24 \mathrm{~h}$. The surfaces, labeled as A and B after acid and alkaline treatments, respectively, were characterized by contact angle measurements and compared with polished surfaces (control). The sessile drop method was used for the obtaining of the contact radius $R$ and the contact angle $\theta$. For each experiment, deionized water droplets ( $\sim \mu \mathrm{L}$ in volume) were gently deposited on the surfaces in a glass chamber using a calibrated micro syringe. A CCD camera recorded the side-view images of the drops. At least five different measurements were performed in different areas of each sample and the contact angles were measured. The ambient humidity and temperature were kept at $50 \pm 10 \%$ and $25 \pm 2{ }^{\circ} \mathrm{C}$, respectively. The contact line dynamics were obtained from contact radius $R$ $(t)$ and contact angle $\theta(t)$ measurements as a function of the time, immediately after disconnection of the drop and needle. The equilibrium contact angle $\left(\theta_{e}\right)$ was measured after accommodation of the drop on the surfaces and before the liquid begins to evaporate. The chamber remained closed during the experiments to avoid the influence of external air flow. Dimethyl sulfoxide droplets were placed on the samples under the same experimental conditions and the free energy was calculated from polar-non polar liquids pair approaches based on dispersive $\left(\gamma^{d}\right)$ and polar $\left(\gamma^{p}\right)$ components [23].

\subsection{Coatings}

Both A and B surfaces of cp-Ti and Ti6Al4V were coated with three different ceramic materials prepared by the solgel method. The first colloidal precursor solution was obtained mixing acetic acid, isopropyl alcohol, nitric acid, distilled water and isopropoxy titanium. After immersion in the fluids, the samples were subjected to a heat treatment at $400{ }^{\circ} \mathrm{C}$ and labeled $\mathrm{A} 1$ and $\mathrm{B} 1$ for acid and alkaline substrates, respectively. The second precursor solution was obtained from the same precursor established in the previous route for $\mathrm{A} 1$ and $\mathrm{B} 1$ with the addition of calcium nitrate and hydrated isopropyl alcohol. After coating and 
Fig. 1 Representation of the method used for the strength test of the coatings and different failures modes adapted from DeFeslko*

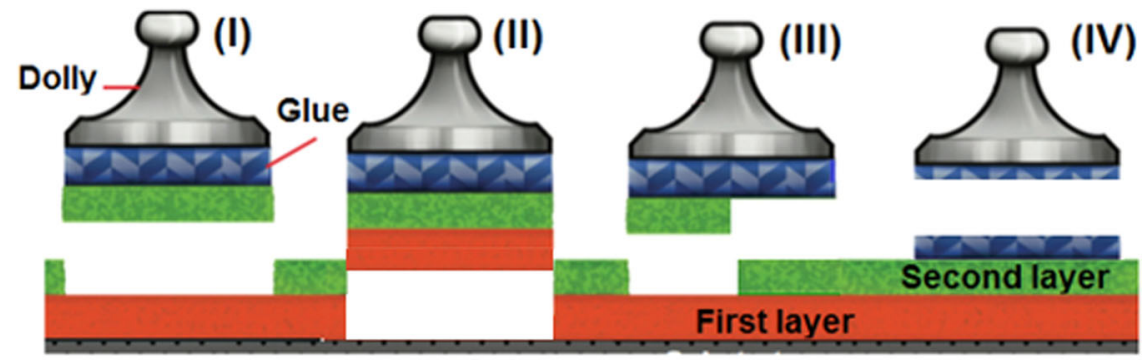

Substrate the heat treatment, the surfaces were labeled A2 and B2. The last precursor solution was obtained from the mixture of phosphoric acid $\left(\mathrm{H}_{3} \mathrm{PO}_{4}\right)$, ethyleneglycol $\left(\mathrm{C}_{2} \mathrm{H}_{6} \mathrm{O}_{2}\right)$ and methanol. The chemical precursors were condensed at 50-100 ${ }^{\circ} \mathrm{C}$ under constant magnetic stirring, until a specific density with colloidal particles was achieved. The procedure yielded an opaque and viscous gel. The samples were submerged in the solution, subjected to a thermal treatment at $700{ }^{\circ} \mathrm{C}$ and labeled A3 and B3. The synthesis and thermal annealing processes provided a ceramic of multicrystalline phases and reduced strain-stress lattice defects [24, 25]. The adhesion and stability of the coatings on the acid and alkaline substrates was investigated by strength tests, performed by a Pull-off adhesion tester (PosiTest AT-D, DeFelsko Corporation, Ogdensburg, USA) in accordance with international standards ASTM D4541/D7234, AS/NZS 1580.408.5 and ISO 4624/16276-1e. At least four different measurements were performed in different substrates with $5 \mathrm{~cm}^{2}$ area and $2 \mathrm{~cm}^{2}$ area dolly. Figure 1 shows a schematic representation of the method used to test the adhesion of the coatings. After preliminary testing several types of glues, Araldite 2011 and Araldite Hobby were selected due to their better performance with all the coatings after $20 \mathrm{~h}$ of drying. Our interest is to investigate four different failures modes of pull-off tests, identified by adhesive fracture with failures of the second layer (I), cohesive fracture with failures of the first layer (II), partial failures (III) and glue failure (IV).

\subsection{Biological assay}

The biological performance was investigated through (i) qualitative analyses of osteoblastic cells response on negatively-positively charged $\mathrm{cp}$ - $\mathrm{Ti}$ and (ii) quantitative analyses of fibroblastic cells response on negativelypositively charged Ti6Al4V with different coatings.

Osteoblastic cells of rabbits were placed in a culture medium with $3.0 \mathrm{~mL}$ of HAM F12-DMEM (Dubelco's Modified Eagle Medium) at 1:1 ratio, supplemented with $20 \%$ bovine fetal serum and $1 \%$ penicillin/streptomycin and incubated in an oven at $38{ }^{\circ} \mathrm{C}\left(95 \%\right.$ humidity, $\left.5 \% \mathrm{CO}_{2}\right)$. The cultures were renewed every 3 days and always in the same period for the promotion of the physiological timing of the cell division. The cultures were periodically observed under an inverted microscope for the verification of the cell proliferation and to avoid cell overpopulations in longer periods. The $\mathrm{pH}$ was set at 7 . When an intense cellular growth was observed, the cells were separated through a treatment with trypsin (Trypsin Solution-Versene-Instituto Adolfo Lutz). The cell suspensions were centrifuged at $1000 \mathrm{rpm}$ for $5 \mathrm{~min}$ and the phases were separated, the supernatant was discarded and $2 \mathrm{~mL}$ of the culture medium at $38^{\circ} \mathrm{C}$ were added to the cell pellet. Detached cells were diluted in $1 \mathrm{~mL}$ Trypsin and the dead cells were identified by the addition of $20 \mu \mathrm{L}$ Trypan Blue. The samples were examined in a Neubawer chamber at four quadrants. Stained cells were discarded and the total number of cells was divided by 4 and multiplied by 20,000 (the dilution factor). The number of viable cells was $0.8 \times 10^{15}$. The cells were deposited on Ti metal surfaces in culture wells and left to rest for $2 \mathrm{~h}$. Subsequently, culture, serum and antibiotics were added and the samples remained at $37^{\circ} \mathrm{C}$ for $48 \mathrm{~h}$. Finally, the samples were fixed with $2.5 \%$ glutaraldehyde for $24 \mathrm{~h}$, washed in a $0.1 \mathrm{M}$ phosphate buffer solution at $\mathrm{pH}$ 7.3), and fixed with $1 \%$ osmium tetroxide in the same buffer (30 min). Dehydration was carried out with increasing ethyl alcohol concentrations for the drying of the material through the critical point technique (CPD 020, Balzers Union) with liquid $\mathrm{CO}_{2}$. The specimens were mounted on appropriate stubs, sputter-coated with 20-nm gold (MED 010, Balzers Union) and characterized by scanning electron microscopy (Philips SEM 515).

Quantitative analyses were performed by the cells viability test based on the reduction of bromide of 3-(4,5dimethyl thiazol-2-yl)-2,5-diphenyl tetrazolium bromide (MTT). L929 cells with $2 \times 10^{5}$ cells $/ \mathrm{ml}$ were added in 30 , 50 and $100 \mu \mathrm{L}$ volumes. After $72 \mathrm{~h}$ of culture, the supernatant was removed and $200 \mu \mathrm{L}$ of $1 \mathrm{mg} / \mathrm{mL}$ MTT in complete RPMI were added. The cells were incubated for 3 $\mathrm{h}$ at $37{ }^{\circ} \mathrm{C}$ and $5 \% \mathrm{CO}_{2}$. The supernatant was then removed, the cells were solubilized through the addition of $200 \mu \mathrm{L}$ dimethyl sulfoxide and seeded $(30 \mu \mathrm{L})$ in sample plate holes. Their viability was evaluated through the addition of MTT. All biocompatibility tests followed the protocols preestablished by the Institute of Bioscience, UNESP, in 
Fig. 2 Typical results of wettability kinetics obtained by the monitoring contact angle and contact radius as a function of time on polished (a), acid (b) and alkaline (c) Ti6Al4V surfaces and the normalized contact radius (d) and contact angle (inset) as a function of the normalized time for three different surfaces. Dashed lines indicate the equilibrium contact angle $\theta_{\mathrm{e}}$
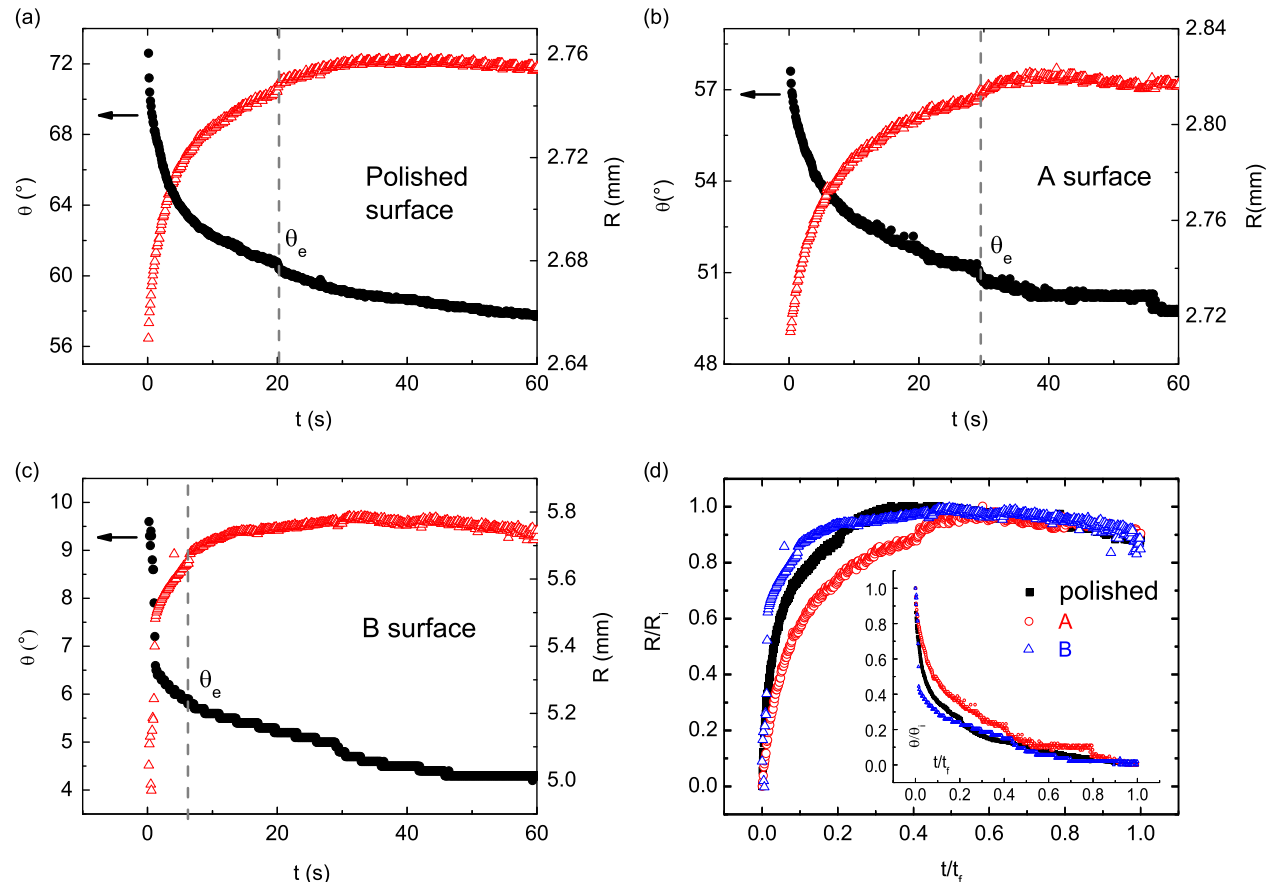

(d)

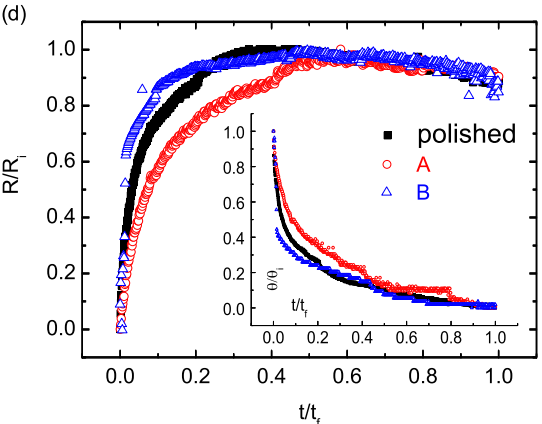

accordance with ISO 10993, 1, 5 and 6 steps [26]. The optical density values ODs obtained for the samples coated with cells were compared two by two by the Mann-Whitney statistical approach [27]. The non-parametric analysis technique indicates the hypothesis of equality between groups, at 0.05 significance level, when $p<0.05$. Complete results are provided in the Supplementary material.

\section{Results}

\subsection{Characterization of positive-negative surfaces}

Figure 2 shows typical results of contact angle $\theta$ and contact radius $R$ of water droplets as a function of the time elapsed after they have been deposited on polished, acid A and alkaline B Ti6Al4V surfaces. Just after being dripped, the drop advanced on the surfaces forming an interface until it reached an equilibrium state with $R=2.76 \mathrm{~mm}, 2.82 \mathrm{~mm}$, $5.7 \mathrm{~mm}$ and $\theta_{\mathrm{e}}=58^{\circ}, 40^{\circ}, 6^{\circ}$ for polished, acid and alkaline treatments, respectively. The high hydrophilicity of the alkaline surface was corroborated by the fast spreading of the liquid and low equilibrium contact angle. Figure $2 d$ shows the normalized $R / R_{\mathrm{i}}$ contact radius and the $\theta / \theta_{\mathrm{i}}$ contact angle (inset) plotted against $t / t_{\mathrm{f}}$, where $R_{i}$ is the initial contact radius, $\theta_{\mathrm{i}}$ is the initial contact angle and $t_{\mathrm{f}}$ is the final temperature. The results revealed the different wettability kinetics in which the movement of the contact line is delayed on acid surfaces. An opposite situation was observed for the alkaline surface. Therefore, the accommodation of the drop on the surface depended on the acid or
Table 1 Total surface free energy and its polar $\left(\gamma^{\mathrm{p}}\right)$ and dispersive $\left(\gamma^{\mathrm{d}}\right)$ components (with standard deviation) obtained from equilibrium contact angle measurements of polished, acid and alkaline treated surfaces of cp-Ti and Ti6Al4V samples

\begin{tabular}{llcl}
\hline $\mathrm{cp}-\mathrm{Ti}$ & $\gamma^{d}\left(\times 10^{-3} \mathrm{Jm}^{-2}\right)$ & $\gamma^{p}\left(\times 10^{-3} \mathrm{Jm}^{-2}\right)$ & $\gamma\left(\times 10^{-3} \mathrm{Jm}^{-2}\right)$ \\
\hline Polished & $25 \pm 1.5$ & $8.5 \pm 1.5$ & 33.5 \\
Acid & $40 \pm 1$ & $1 \pm 1$ & 41 \\
Alkaline & $23 \pm 2$ & $14 \pm 2$ & 37 \\
Ti6A14V & & & \\
Polished & $8.5 \pm 1$ & $60 \pm 1$ & 68.5 \\
Acid & $11 \pm 2$ & $38 \pm 2$ & 49 \\
Alkaline & $10 \pm 2$ & $70.5 \pm 2$ & 80.5 \\
\hline
\end{tabular}

alkaline treatments due to different wetting degrees. Similar wettability kinetics was observed for cp-Ti and Ti6Al4V. Table 1 shows the free energy of surfaces $\gamma_{s}$ calculated through the equilibrium contact angle $\theta_{e}$ measurements.

Figure 3 shows scanning electron micrographs of osteoblastic cells adhered and spread evenly over the entire acid (Fig. 3a, b) and alkaline (Fig. 3c, d) surfaces with 250 and 500 magnifications. Such cells are important for tissue repair process and their morphologies associated with the size indicate the first stage of the bone growth on both surfaces. The cell viability was evaluated for acid-alkaline (A-B) surfaces and three different coatings on Ti6Al4V. Table 2 shows the optical density OD $(\lambda=492 \mathrm{~nm})$ values of cell cultures in 12 independent experiments. Figure 4 shows the average results of the growth of L929 cells on the surfaces in four independent experiments. 
Fig. 3 Micrographs of cells adhered and spread on positive (3a and $3 \mathbf{b})$ and negative ( $3 \mathbf{c}$ and 3d) Ti surfaces obtained by SEM with $250 \times$ and $500 \times$ magnification
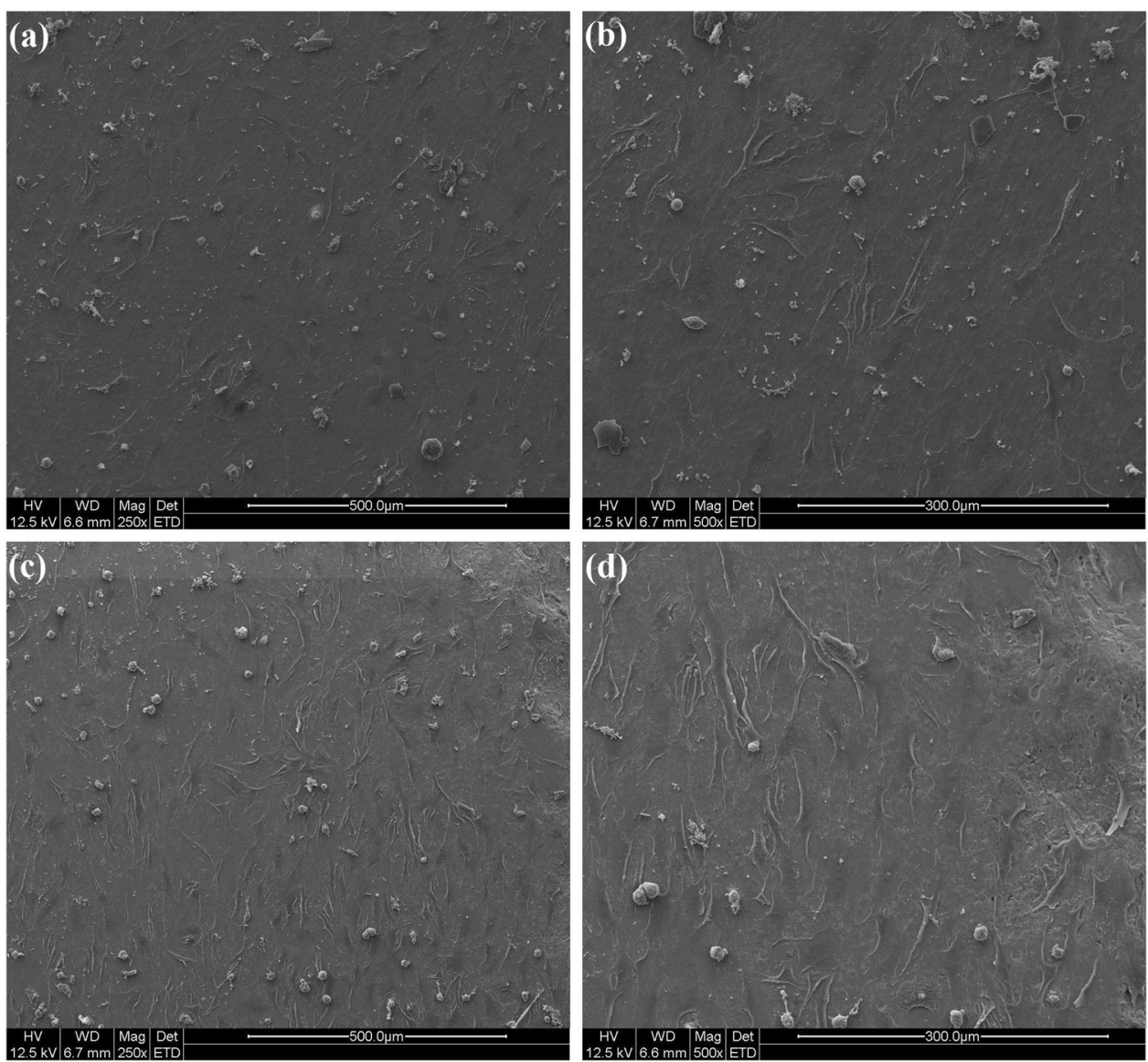

Table 2 Values of optical density of L929 cells on A-B Ti6Al4V surfaces with different coatings

\begin{tabular}{lllllllll}
\hline Control & A & A1 & A2 & A3 & B & B1 & B2 & B3 \\
\hline 0.126 & 0.156 & 0.115 & 0.064 & 0.741 & 0.12 & 0.09 & 0.079 & 0.894 \\
0.107 & 0.09 & 0.106 & 0.078 & 0.746 & 0.088 & 0.205 & 0.076 & 0.789 \\
0.12 & 0.113 & 0.064 & 0.062 & 1.42 & 0.113 & 0.105 & 0.075 & 0.789 \\
0.112 & 0.13 & 0.134 & 0.076 & 1.172 & 0.101 & 0.089 & 0.076 & 0.901 \\
0.221 & 0.265 & 0.256 & 0.144 & 1.102 & 0.207 & 0.286 & 0.212 & 1.201 \\
0.239 & 0.304 & 0.411 & 1.03 & 0.724 & 0.155 & 0.273 & 0.162 & 0.745 \\
0.293 & 0.248 & 0.287 & 0.167 & 0.998 & 0.189 & 0.235 & 0.219 & 0.806 \\
0.315 & 0.299 & 0.298 & 0.244 & 0.834 & 0.208 & 0.211 & 0.317 & 0.836 \\
0.287 & 0.301 & 0.263 & 0.146 & 0.779 & 0.165 & 0.118 & 0.11 & 0.863 \\
0.189 & 0.289 & 0.378 & 0.147 & 1.115 & 0.241 & 0.237 & 0.136 & 0.797 \\
0.265 & 0.297 & 0.326 & 1.264 & 0.789 & 0.223 & 0.119 & 0.107 & 0.836 \\
0.299 & 0.313 & 0.305 & 0.168 & 0.814 & 0.114 & 0.246 & 0.098 & 0.811 \\
\hline
\end{tabular}

The statistical analyses for the acid and alkaline treatment (inset on Fig. 4) revealed a significant difference regarding the cell growth on $\mathrm{A}$ and $\mathrm{B}$ surfaces, i.e. $p=$ 0.0262. In comparison to the control group, the negative surfaces inhibited the cell response. An opposite situation was observed for $\mathrm{cp}-\mathrm{Ti}$, in which the acid treatment decreased the cell viability. However, the analysis of the

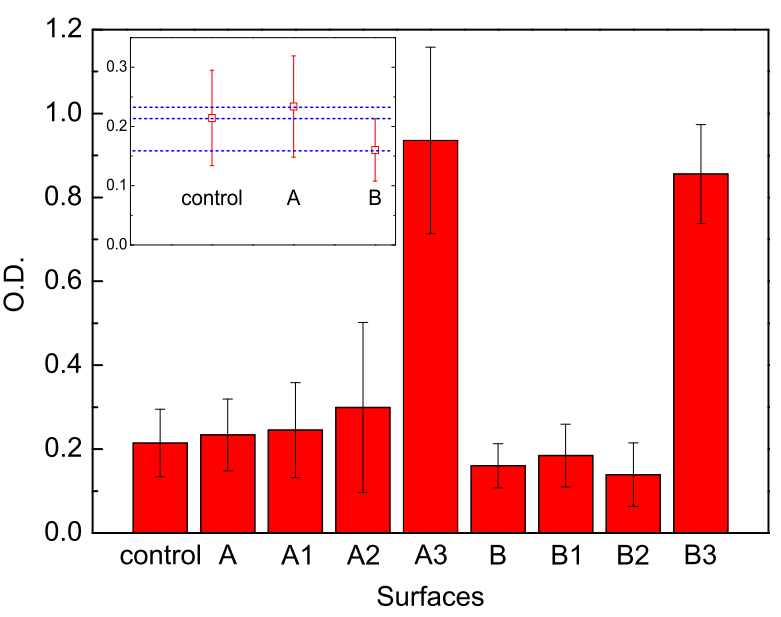

Fig. 4 Average and standard deviation of optical density with $\lambda=492$ nm of L929 cultures grown on positive (a) and negative surfaces (b) with respective coatings (1,2 and 3) of Ti6Al4V and control cells cultured in the absence of titanium. On the inset is presented the statistical analyses of acid and alkaline treatments

coatings revealed no significant difference between $\mathrm{A} 1$ and $\mathrm{B} 1(p=0.0735), \mathrm{A} 2$ and $\mathrm{B} 2(p=0.5637)$ and $\mathrm{A} 3$ and $\mathrm{B} 3$ $(p=1)$ by Mann-Whitney test, i.e., the cells on the coatings are not sensitive to acid or alkaline intermediate treatments, 
Fig. 5 Test of adhesion of different coatings obtained in four independent experiments (MPa) for $\mathrm{cp}-\mathrm{Ti}$ and Ti6Al4V

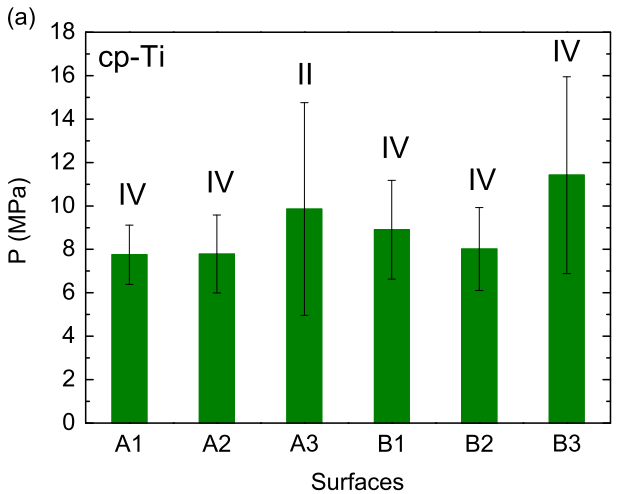

since the coatings act as a barrier between charged surfaces and the cells.

The second key aspect of the cell response is related to the type of surface, i.e., the ability of surfaces A3 and B3 to improve biocompatibility. The equality among A, A1, A2 and $\mathrm{A} 3$ groups was rejected by the Kruskal-Wallis tests [27] $(p \approx 0)$. Therefore, the groups were compared by Student Newman Keuls [27] test and the results have shown a highly significant difference for A3 and B3 groups where the values is $0.95 \pm 0.23$ and $0.86 \pm 0.12$, respectively, while for the control groups the value is $0.21 \pm 0.08$. On the other hand, A, A1, A2 are equal to each other. Similar results were found for B, B1, B2 groups. All statistical results are provided in the Supplementary material (Supplementary Table 1, 2 and 3).

\subsection{Coating adhesion}

Figure 5 shows the adhesion values for surfaces A and B of cp-Ti and Ti6Al4V with different coatings in four independent measurements conducted in 48 experiments. A mode IV in pull-off was observed for most tests. The partial (mode III) and total (modes I and II) failures of the coatings were observed and are represented by $*$ and $* *$, respectively. Although A3 coating on cp-Ti and Ti6Al4V and B2 coating on Ti6Al4V presented good adhesion, the interface has shown poor stability. A substantial increase in adhesion was observed for the B3 coating on Ti6Al4V with failure mode IV.

\section{Discussion}

An "ideal" bone-implant interface requires specific characteristics, since the bone-connection depends on adhesion and stability at titanium coating-cells interfaces. From a materials science point of view, the coating plays a key role on the functionalization of implants due to the type of titanium oxide and/or titanate formed on the interfaces. Our results show the effect of simple acid-alkaline treatments on specific properties that has not been previously investigated [22]. Herein, the surfaces were characterized regarding wettability, total surface free energy and its components. Such properties were clearly changed by the treatments. The contact line between the surface and the liquids appears to be very sensitive to the negatively charged surfaces. For instance, Ti6Al4V presented high surface free energy with high polar component, rapid advancing of the contact line and a very low contact angle when the surface was negatively charged through an alkaline treatment (Table 1 and Fig. 2). The positive (acid) and negative (alkaline treatment) charging of Ti surfaces were attested by the decrease and increase of $\gamma^{p}$, respectively (Table 1). Variations in the contact radius and contact angle as a function of time correspond to wettability kinetics $V$ when the contact line moves toward reaching an equilibrium state and establishing an interface [28]. According to contact angle $\theta_{\mathrm{e}}$ and speed of advance of contact radius $\Delta \mathrm{R} / \Delta \mathrm{t}$, the relation between the wettability kinetics is $V_{\mathrm{B}} \approx$ $30 \times V_{\mathrm{A}}$. On the other hand, the alkaline treatment modified the hydrophilicity of the surfaces, whereas the values of $\theta_{\mathrm{e}}$ decreased and reached a minimum value of $5^{\circ}$ for negatively charged Ti6Al4V. The small contact angle associated with the large contact radius in an equilibrium state indicates a pinned contact line. Such a configuration is characteristic of the hydrophilic surface in Wenzel state [29]. The differences between the contact angles are attributed to morphology and free energies $\gamma$ of the surfaces after chemical-heat treatments. These properties affect the solidliquid surface tension $\gamma_{\mathrm{sl}}$. According to wetting state of the acid and alkaline surfaces the relation between the solidliquid surface tension is $\gamma_{\mathrm{sl}(\mathrm{B})} \approx 2.4 \gamma_{\mathrm{sl}(\mathrm{A})}$.

The wettability of implant surfaces in terms of biological and clinical aspects has been reviewed [30] while some works have discussed the correlation among wettability, free energy and hemocompatibility [31], as well as the correlation among spatial dimensions of surfaces, cell response and free energy [32-34]. We have also studied the influence of the wetting properties on the biological properties. According to Fig. 3, no significant difference in 
the morphology of osteoblast cells on positively and negatively charged surfaces. However, more cells were observed on negatively charged surfaces. On the other hand, the quantitative analyses that employed fibroblast cells revealed that the negatively charged surfaces with small contact angles inhibited biocompatibility of Ti6Al4V, while the positively charged surfaces with larger contact angles inhibited the cell response on $\mathrm{cp}-\mathrm{Ti}$, as reported in previous studies conducted with the same methodology [25]. The high hydrophilicity obtained by the negatively charged surface was not effective for some Ti-based alloys. In fact, the effect of the positively-negatively charged surfaces on cells response depends on the type of titanium implants and the hydrophilic state. However, the results of the cell viability indicated no significant difference in the cell growth on the surfaces with A1, A2, B1 and B2 coatings.

The influence of positively-negatively surfaces on the adhesion forces of different types of ceramic coatings and qualitative-quantitative biological assay regarding wettability aspects represents the novelty in this study. Three different coatings were developed for the analyses of the usefulness of simple chemical treatments regarding modifications in the Ti metal surfaces and adhesion strength of the coatings. According to the results, the adhesion strengths were close to $17 \mathrm{MPa}$ (Fig. 5) equivalent to 3400 $\mathrm{N}$ taking into account the dimensions of the substrate-dolly interface. Such value is hundred times higher than the values obtained for bioactive coatings for $\mathrm{cp}-\mathrm{Ti}$ and Ti6A14V obtained by similar simple chemical treatments [35]. The high bond strength can be attributed to high surface free energy and roughness. The combination of such properties characterizes the wetting state and increases the forces at the interface. Focusing on A3 and B3 surfaces, due to interesting biocompatibility properties (as shown in Fig. 4), preliminary experiments have revealed poor adhesion and stability of calcium phosphate coatings. Therefore, a multilayered structure with coatings 1 and 2 was developed as intermediary layers between A-B and A3-B3 followed by a specific thermal treatment. The science behind of such an experimental procedure for the production of the coatings with multilayered interfaces is based on the concept of ion diffusion through oxide layers for the creation of titanates on surfaces. This approach provides good crystallographic orientation with subsequent strong bonds. As a consequence, distant particles can interact with each other and the charge fluctuation increases the long-range forces. The major contribution for such enhancement of energy is attributed to polar component $\gamma^{p}$. On the other hand, for A surfaces, the possibility of interactions between $\mathrm{H}^{+}$and remaining $\mathrm{Ti}$ metallic groups may be the cause of the decreasing $\gamma^{p}$ for cp-Ti and Ti6Al4V substrates. The striking features of the negatively charged surfaces are related to the influence of available $\mathrm{OH}^{-}$groups on the surface attested by the increasing of the $\gamma^{p}$ for both substrates and attributed to the diffusion of $\mathrm{Na}^{+}$through alkaline heattreatment with $\mathrm{NaOH}$. A similar phenomenon can be expected at the interface with $\mathrm{Ca}_{2}{ }^{+}$in coating $\mathrm{A} 2$, explained by titania phase transformations at the intermediary layer between $\mathrm{Ti}$ and $\mathrm{CaP}$ at $700{ }^{\circ} \mathrm{C}$ (see thermal analyses of $\mathrm{TiO}_{2}$ in the Supplementary material) that change the availability of $\mathrm{OH}^{-}$through ionic exchange at the oxide multilayer. The results of adhesion have revealed values close to $3400 \mathrm{~N}$, required for the detachment of glues from the substrate. Even after the tests, the coatings remained stable. The formation of $x \mathrm{TiO}_{3}$ with $x=\mathrm{Na}_{2}$ or $\mathrm{Ca}$ and a consequent physical-chemical modification on the surfaces can explain the interesting mechanical properties of the coating. The effect of the phase transformation of $\mathrm{TiO}_{2}$ subjected to a thermal treatment is a fundamental step for modifications in the multilayer and interface bonding.

From a technological point of view, several techniques can be applied for the deposition of $\mathrm{TiO}_{2}$ coatings on metallic surfaces. However, the deposition of $\mathrm{TiO}_{2}$ as well as calcium phosphate films as uniform layers on substrates of different geometries is a difficult task. Regardless the processing, economic viability is required. In addition to the simple acid-alkaline treatments, the processing of coating materials of different geometries by immersion in a colloidal solution followed by specific thermal treatments modifies the atomic structures on irregular surfaces in most metallic implants. In addition to biocompatibility and good mechanical behavior, polycrystalline $\mathrm{CaP}$ can act as reservoir of $\mathrm{Ca}$ and $\mathrm{P}$ ions. In a biological environment, such materials optimize tissue regeneration by creating a gradient of cell proliferation $[5,6,9]$. If, on the one hand, the biocompatibility of A3-B3 coatings is attributed to the chemical heterogeneity of $\mathrm{CaP}$, the high adhesion of the multilayered structure is attributed to sodium and calcium diffusion at the first and second oxide interfaces, respectively. The final result is a heterogeneous surface composed of $\mathrm{CaP}$ nanoparticles adhered to cracked titania on positively-negatively charged surfaces, as shown in Fig. 6 . Such processing may solve the problems related to mechanical stability at titanium substrate-coating interfaces that hinders its use for clinical applications. This result represents an important surface feature, since a bioactive coating for implants requires adhesion, stability and bone anchorage.

\section{Conclusions}

The effects of positively-negatively charged surfaces on biocompatibility and adhesion forces were studied for different ceramic coatings on metallic surfaces. The materials (cp-Ti and Ti6Al4V) were subjected to acid and 
Fig. 6 SEM micrographs with a $2000 \times$, b $5000 \times$, and c $10000 \times$ magnification of the multilayered structure for an optimized Ti6Al4V-CaTiO ${ }_{3}$ $\mathrm{CaP}$ surface
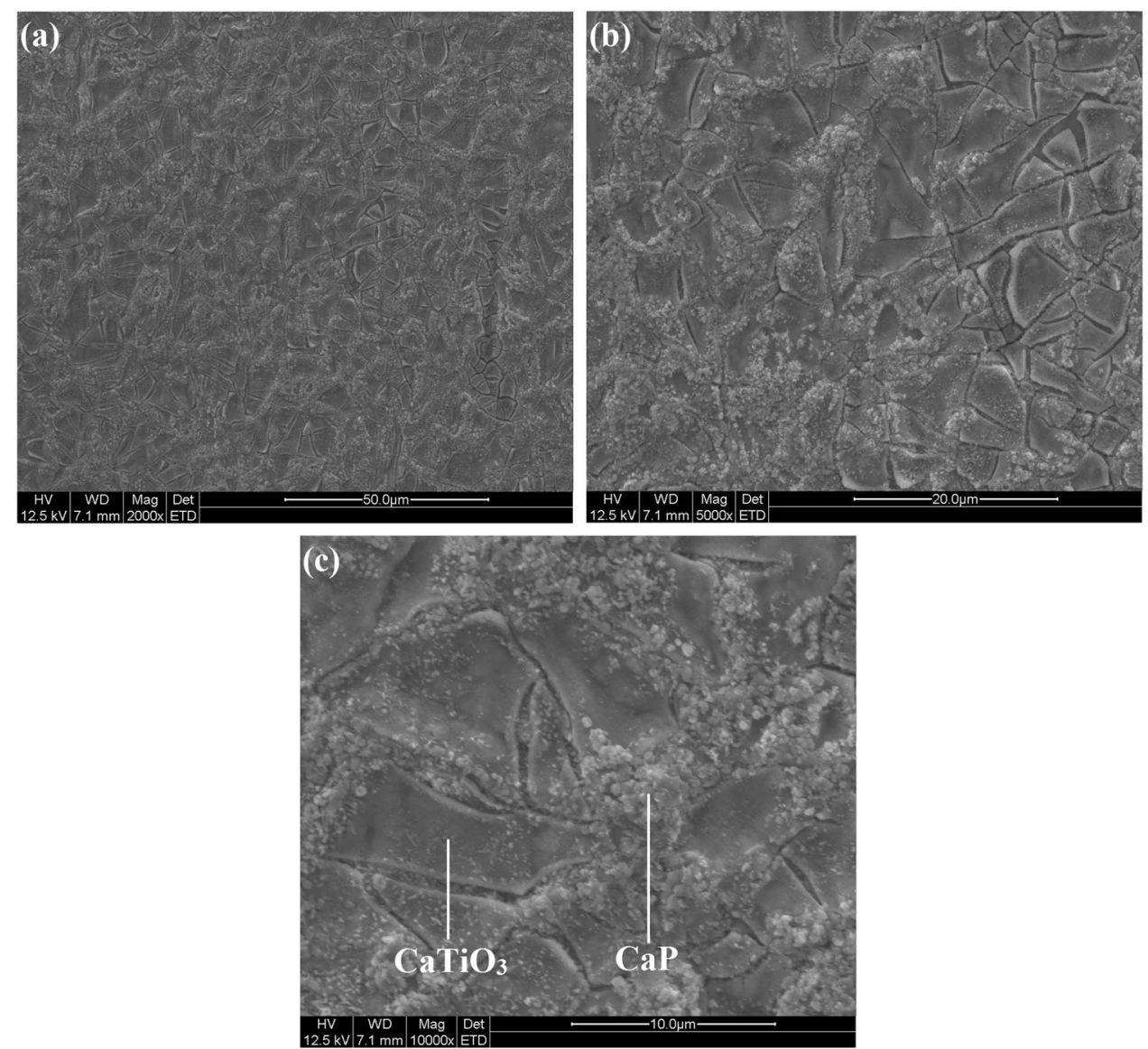

alkaline treatments. The investigation was focused on the mechanical properties in terms of adhesion, stability and modes of failures of the interfaces through strength testes. The surfaces were characterized by contact line and contact angle measurements whereas a hydrophilic state was found for negatively charged Ti6Al4V. The surface free energy was obtained from the polar-apolar pair approach and both acid and alkaline treatments activated cp-Ti, whereas only the alkaline treatment activated Ti6Al4V. The chemical treatments increase wettability and adhesion. Both A and B surfaces improved the adhesion and proliferation of osteoblastic cells. On the other hand, toxic effects were observed on negatively charged surfaces. The results of statistical analyses revealed no significant differences of the biocompatibility of $\mathrm{TiO} 2$ and $\mathrm{CaTiO} 3$ (A1, B1 and A2, B2 groups respectively). However, the calcium phosphate coating significantly improved the viability of the cells. Finally, and perhaps the most important finding, the highest adhesiveness and cell responses of B3-Ti6Al4V are the first step towards the obtaining of an optimized surface as a promising candidate for implant purposes. The corrosion properties of the B1 and B2 layers as well as new biocompatibility tests of the material are currently under studies.
Acknowledgements The authors are indebted to Dr. Douglas Monteiro and Dr. Elisabete Zaniquelli (USP-Ribeirao Preto); Dr. Dayse Santos and Juliana Ferreira (UNESP-Bauru); Dr. Ligia Mota, Dr. Ramon Kaneno, Dr. Tereza Peraçoli and Dr. Margarida Saeki (UNESP-Botucatu), Dr. Marcelo Carbonari (INSPER) and Angela Giampedro (USP-Sao Carlos) for all the support. They also acknowledge the financial support provided by Brazilian Agencies CAPES, CNPq and FAPESP.

\section{Compliance with ethical standards}

Conflict of interest The authors declare that they have no competing interest.

\section{References}

1. Wu C, Chen Z, Wu Q, Yi D, Friis T, Zheng X, Chang J, Jiang X, Xiao Y. Clinoenstatite coatings have high bonding strength, bioactive ion release, and osteoimmunomodulatory effects that enhance in vivo osseointegration. Biomaterials. 2015;71:35-47.

2. Echeverry Rendón M, Galvis O, Giraldo DQ, Pavón J, LópezLacomba JL, Jiménez-Piqué E, Anglada M, Robledo SM, Castaño JG, Echeverría F. Osseointegration improvement by plasma electrolytic oxidation of modified titanium alloys surfaces. J Mater Sci Mater Med. 2015;26:72. 
3. Nayak S, Dey T, Naskar D, Kundu SC. The promotion of osseointegration of titanium surfaces by coating with silk protein sericin. Biomaterials. 2013;34:2855-64.

4. Rungsiyakull C, Li Q, Sun G, Li W, Swain MV. Surface morphology optimization for osseointegration of coated implants. Biomaterials. 2010;31(Issue 27):7196-204.

5. Thein-Han LJ, Xu HH. Calcium phosphate cement with biofunctional agents and stem cell seeding for dental and craniofacial bone repair. Dent Mater. 2012;28:1059-70.

6. Guha AK, Singh S, Kumaresan R, Nayar S, Sinha A. Mesenchymal cell response to nanosized biphasic calcium phosphate composites. Colloids Surf B Biointerfaces. 2009;73:146-51.

7. Dorozhkin SV. Biocomposites and hybrid biomaterials based on calcium orthophosphates. Biomatter. 2011;3:56.

8. Mussano F, Genova T, Munaron L, Faga MG, Carossa S. Ceramic Biomaterials for Dental Implants: Current Use and Future Perspectives. 2016. doi:10.5772/62701.

9. Metikos-Hukovic M, Tkalcec E, Kwokal A, Piljac J. An in vitro study of $\mathrm{Ti}$ and Ti-alloys coated with sol-gel derived hydroxyapatite. Surf Coat Technol. 2003;165:40-50.

10. Goriainov V, Cook R, Latham JM, Dunlop DG, Oreffo ROC. Bone and metal: An orthopaedic perspective on osseointegration of metals. Acta Biomaterialia. 2014;10:4043-57.

11. Wanga Y, Yub H, Chena C, Zhaoa Z. Review of the biocompatibility of micro-arc oxidation coated titanium alloys. Mater. Des. 2015;85:640-652.

12. Blanquer A, Hynowska A, Nogués C, Ibáñez E, Sort J, Baró MD, Ozkale B, Pané S, Pellicer E, Barrios L. Effect of surface modifications of Ti40Zr10Cu38Pd12 bulk metallic glass and Ti-6Al$4 \mathrm{~V}$ alloy on human osteoblasts in vitro biocompatibility. PLoS ONE. 2016;11:e0156644.

13. Zhao CQ, Wu SQ, Lu YJ, Ga YL, Guoa S, Lin JJ, Huang TT, Lin $J X$. Evaluation to the effect of $\mathrm{B}_{2} \mathrm{O}_{3}-\mathrm{La}_{2} \mathrm{O}_{3}-\mathrm{SrO}-\mathrm{Na}_{2} \mathrm{O}-\mathrm{Al}_{2} \mathrm{O}_{3}$ bonding agent on Ti6Al4V-porcelain bonding. J Mech Behav Biomed Mater. 2016;63:75-85.

14. Mandracci P, Mussano F, Rivolo P, Carossa S. Surface treatments and functional coatings for biocompatibility improvement and bacterial adhesion reduction in dental implantology. Coating. 2016;6:7. doi:10.3390/coatings6010007.

15. Shukla AK, Balasubramaniam R. Effect of surface treatment on electrochemical behavior of $\mathrm{CP} \mathrm{Ti}, \mathrm{Ti}-6 \mathrm{Al}-4 \mathrm{~V}$ and $\mathrm{Ti}-13 \mathrm{Nb}-13 \mathrm{Zr}$ alloys in simulated human body fluid. Corros Sci. 2006;48:1696-720.

16. Zhou R, Wei D, Yang H, Cheng S, Feng W, Li B, Wang Y, Jia D, Zhou Y. Osseointegration of bioactive microarc oxidized amorphous phase $/ \mathrm{TiO}_{2}$ nanocrystals composite coatings on titanium after implantation into rabbit tibia. J Mater Sci Mater Med. 2014;25:1307-18.

17. Chen X-B, Li YC, Plessis JD, Hodgson PD, Wen C. Influence of calcium ion deposition on apatite-inducing ability of porous titanium for biomedical applications. Acta Biomater. 2009;5: 1808-20.

18. Minagar S, Wang J, Barndt CC, Ivanova EP, Wen C. "Cell response of anodized nanotubes on titanium and titanium alloys". J Biomed Mater Res Part A 2013;101:2726-39.

19. Diefenback M, Muckley T, Shrader C, Schmidt J, Zankovych S, Bossert J, Jandt KD, Faucon M, Finger U. The effect of plasma chemical oxidation of titanium alloy on bone-implant contact in rats. Biomaterials. 2011;32:8041-7.

20. Echiato-filho AJ, da Silva Vieira Marques I, dos Santos DM, Matos AO, Rangel EC, da Cruz NC, Barão VAR. Effect of nonthermal plasma treatment on surface chemistry of commercially-pure titanium and shear bond strength to autopolymerizing acrylic resin. Mater Sci Eng C Mater Biol Appl. 2016;60:37-44.

21. Kokubo T, Yamaguchi S. Bioactive titanate layers formed on titanium and its alloys by simple chemical and heat treatments. Open Biomed Eng J. 2015;9:29-41.

22. Wang XJ, Li YC, Lin JG, Hodgson PD, Wena CE. Apatite inducing ability of titanium oxide layer on titanium surface: the effect of surface energy. J Mater Res. 2008;23:1682.

23. Owens DK, Wendt RC. Estimation of the surface free energy of polymers. J Appl Polym Sci. 1969;13:1741.

24. Nascimento RM, Faita FL, Agostini DLS, Job AE, Guimarães FEG, Bechtold IH. Production and characterization of natural rubber-Ca/P blends for biomedical purposes. Mater Sci Eng $\mathrm{C}$ Mater Biol Appl. 2014;39:29-34.

25. Nascimento R, Carvalho V. Dynamics of the interaction between body fluid and $\mathrm{Cp}$-Ti: the influence of surface functionalization in the first stages of osseointegration. Braz $\mathrm{J}$ Biomed Eng. 2014;30:83-90.

26. Nascimento R, Carbonari M, Florentino A. Development of a high adhesion bioactive coating for implant dentistry purposes. Implant News. 2013;10:6.

27. Zar, JH Biostatistical Analysis. $4^{\mathrm{a}}$ ed. Upper Saddle River, NJ: Prentice Hall; 1999.

28. Gennes PG. Wetting: statics and dynamic. Rev Mod Phy. 1985;57:827-63.

29. Wenzel RN. Resistance of solid surfaces to wetting by water. Ind Eng Chem. 1936;28:988.

30. Gittens RA, Scheideler L, Rupp F, Hyzy SL, Geis-Gerstorfer J, Schwartz Z, Boyan BD. A review on the wettability of dental implant surfaces II: Biological and clinical aspects. Acta Biomaterialia. 2014;10:2907-18.

31. Svetlana AS, Daniel S, Erik H, Markus R. Evaluation of wettability and surface energy of native Nitinol surfaces in relation to hemocompatibility. Mater Sci Eng C. 2013;33:127.

32. Park JH, Wasilewski CE, Almodovar N, Olivares-Navarrete R, Boyan BD, Tannenbaum R, Schwartz Z. The response to surface wettability gradients induced by chitosan nanofilms on microtextured titanium mediated by specific integrin receptors. Biomaterials. 2012;33:7386.

33. Gittens RA, Olivares-Navarrete R, Cheng A, Anderson DM, McLachlan T, Stephan I, Geis-Gerstorfer J, Sandhage KH, Fedorov AG, Rupp F, Boyan BD, Tannenbaum R, Schwartz Z. The roles of titanium surface micro/nanotopography and wettability on the differential response of human osteoblast lineage cells. Acta Biomaterialia. 2013;9:6268-77.

34. Zhao G, Raines Al, Wieland M, Schwartz Z, Boyan BD. Requirement for both micro-and submicron scale structure for synergistic responses of osteoblasts to substrate surface energy and topography. Biomaterials. 2007;28:2821.

35. Rakngarm A, Miyashita Y, Mutoh Y. Formation of hydroxyapatite layer on bioactive $\mathrm{Ti}$ and $\mathrm{Ti}-6 \mathrm{Al}-4 \mathrm{~V}$ by simple chemical technique. J Mater Sci Mater Med. 2008;19:1953-61. 